\title{
Effects of Adventitious Buds Regeneration from Three Kinds of Explants in Jatropha curcas
}

\author{
Jianian Tang ${ }^{1}$, Guoxuan Liu ${ }^{1}$, Fuguang Yang ${ }^{1}$, Chuanteng Huang ${ }^{2}$, \\ Kaiyuan Zhou ${ }^{1}$, Sufang Niu ${ }^{1}$, Shaoxia Yang ${ }^{1}$, Yali Yang ${ }^{3}$, Ying Liu ${ }^{1,}$ a, * \\ ${ }^{1}$ Guang Dong Ocean University, Zhanjiang, China. \\ ${ }^{2}$ Hainan Forestry Institute, Haikou, China. \\ ${ }^{3}$ Jiaying University, Meizhou, China \\ aliuying85168@126.com
}

Keywords: Jatropha curcas, Regeneration, Adventitious Buds, Thidiazuron.

\begin{abstract}
An efficient method has been established to induce adventitious buds regeneration from 3 kinds of explants (hypocotyl, cotyledon leaf and leaf) of Jatropha curcas L. All the explants were treated by high concentrations $(5-120 \mathrm{mg} / \mathrm{L})$ of TDZ solution for different soak period (5-80 min) with the regeneration rate significantly enhanced and the quality of the regenerated buds dramatically improved. The best results of adventitious bud's regeneration were detected when explants were treated with 20 $\mathrm{mg} / \mathrm{L} \mathrm{TDZ}$ solution for $20 \mathrm{~min}$ before being inoculated on basic MS medium free of hormone for 30 days. What's more, addition of $0.4 \mathrm{mg} / \mathrm{L} \mathrm{GA}_{3}$ into the elongation medium was the most conducive to the extension of adventitious buds. By applying this method described in our paper, regeneration effect of $J$. curcas was remarkably improved.
\end{abstract}

\section{Introduction}

The extract from Jatropha curcas L. can be applied to produce insecticides and pharmaceutical compounds [1]. What's more, seed oil of J. curcas is high contents ( $40 \%$ to $60 \%)$ and can be used to manufacture "biodiesel" as a desirable replacement for naturally occurring petroleum [2]. However, yield of seeds is comparatively low in many situations. Therefore, for the sake of breeding satisfactory J. curcas cultivated species for improving genetic qualities and yields of seed, genetically modified method is regarded as an ideal solution $[3,4]$.

In most case, adventitious shoot regeneration from the receptor (explants) is the prerequisite of genetic transformation. In order to cultivate new varieties of J. curcas for large-scale production of useful planting material, efficient plant tissue culture methods are essential. However, Previous reports have indicated that it took too long (90-140 days) to gain regenerated entire plant and efficiency of adventitious bud regeneration was low $[5,6]$. By applying our original protocol in this paper, an effective method for obtaining regenerated J. curcas plantlets has been set up. Furthermore, comparatively researches have been done for the adventitious bud regeneration effects of three kinds of explants (hypocotyl, cotyledon leaf and leaf) in J. curcas.

\section{Materials and Methods}

\subsection{Plant Sources}

Grown-up Seeds were gathered from J. curcas trees of number M-3 in planting base at Haikou, Hainan province, China [7].

\subsection{Preparation of Explants}

Leaf explants were obtained from mature J. curcas, sterilized with $2 \%$ sodium hypochlorite $(\mathrm{NaClO})$ for 20 min. Hypocotyl explants and cotyledonary leaf explants were gained from the 5-day-old and 12-day-old sterile seedlings respectively. 


\subsection{Condition of Culture and Preparation of Mediums}

All mediums were put into plant sterile culture room at $25 \pm 2{ }^{\circ} \mathrm{C}$ with 12 -h photoperiod of $60-80$ $\mu \mathrm{mol} \mathrm{m-2 \bullet s-1} \mathrm{intensity} \mathrm{(cool} \mathrm{white} \mathrm{fluorescent} \mathrm{tubes).} \mathrm{Murashige} \mathrm{and} \mathrm{Skoog} \mathrm{(MS)} \mathrm{medium} \mathrm{[8]} \mathrm{was}$ used to all experiments in the present study. The medium $\mathrm{pH}$ was adjusted to $5.8-6.0$ by $1 \mathrm{~mol} / \mathrm{L}$ $\mathrm{NaOH}$ before the mediums were autoclaved at $1.4 \mathrm{~kg} \bullet \mathrm{cm}-2$ for $20 \mathrm{~min}$.

\subsection{Treatment of Explants with Thidiazuron (TDZ) Solution}

TDZ was dissolved with $1 \mathrm{~mol} / \mathrm{L} \mathrm{NaOH}$ and diluted with deionized water to manufacture $0,5,10$, 20, 30, 60 and $120 \mathrm{mg} / \mathrm{L}$ TDZ treating solution, and those solution must be adjusted $\mathrm{pH} 5.8-6.0$ and carried on sterile filtration. Explants were soaked into TDZ solutions for different treat times $(0,5,10$, 20, 40 and $80 \mathrm{~min}$ ). After processing, the explants were put on sterile absorbent paper to take out extra liquid.

\subsection{Regeneration}

Explants were inoculated on basic MS medium free of hormone horizontally for 30 days after treating with TDZ solution for different processing time to induce regeneration of adventitious buds. By comparison, explants were placed on MS medium supplemented with different concentrations of TDZ $(0,0.1,0.25,0.5$ and $1 \mathrm{mg} / \mathrm{L})$ for 30 days $[9,10]$.

\subsection{Elongation of Shoot-buds}

In order to induce shoot-buds elongation, the regenerated adventitious buds were transferred with the parent body (explants) to MS medium supplemented with $0.2 \mathrm{mg} / \mathrm{L}$ kinetin (KT), $0.25 \mathrm{mg} / \mathrm{L}$ indole-3-acetic acid (IAA), $0.5 \mathrm{mg} / \mathrm{L}$ 6-benzyladenine (6-BA) and with different concentrations of gibberellic acid (GA3) $(0,0.1,0.2,0.4,0.6$ and $0.8 \mathrm{mg} / \mathrm{L})$ for 15 days $[9,11]$.

\subsection{Rooting and Acclimatization}

Elongated shoots (at least $1 \mathrm{~cm}$ ) were placed into half-strength MS medium included $0.1 \mathrm{mg} / \mathrm{L}$ indole-3-butyric acid (IBA) for 20 days [9]. Entire regenerated plants were transferred to plastic bottles carefully with sterile sand and soil (1:1) for 15 days. At last, the regenerated plants were planted in the cultured room (temperature $25 \pm 2{ }^{\circ} \mathrm{C}$ and relative humidity $70-80 \%$ ) for further acclimatization.

\subsection{Data Analysis}

All of the experiments were based on an completely random factorial design and 3 times repetitions. Data analysis was accomplished via utilizing SPSS 17.0 software, and data was analyzed for their statistical significance by Duncan's multiple comparison ( $\mathrm{p} \leq 5 \%$ ). The results were demonstrated as average value \pm standard deviation (SD).

\section{Results}

\subsection{Regeneration of Adventitious Buds from Three Types of Explants with Conventional Culture Methods}

Three types of explants were placed directly onto MS medium contained 0.05 to $1 \mathrm{mg} / \mathrm{L}$ of TDZ to induce adventitious buds regeneration by conventional culture approaches in $J$. curcas $[9,10]$. Nevertheless, the regeneration efficiency of adventitious buds was barely satisfactory, and the highest proportion of adventitious buds regeneration $(31.97 \%-42.39 \%)$ and the maximum quantity of induced adventitious buds per explant (3.05-6.53) were obtained subsequently, when $0.5 \mathrm{mg} / \mathrm{L} \mathrm{TDZ}$ was supplemented into the medium (Table 1).

(A) Hypocotyl, (C) cotyledon leaf and (E) leaf were inoculated on MS medium added $0.5 \mathrm{mg} / \mathrm{L}$ TDZ for induction of adventitious buds regeneration for 30 days (bars $=0.5 \mathrm{~cm}$ ); (B) Hypocotyl, (D) cotyledon leaf and (F) leaf were inoculated onto hormone free MS medium for induction of adventitious buds regeneration for 30 days of culture after treatment with $20 \mathrm{mg} / \mathrm{L}$ TDZ solution for $20 \mathrm{~min}$ (bar $=0.5 \mathrm{~cm}$ ); Shoot buds regenerated from $(\mathrm{G})$ hypocotyl, (I) cotyledon leaf, $(\mathrm{K})$ leaf by conventional culture protocol, and adventitious buds regenerated from $(\mathrm{H})$ hypocotyl, $(\mathrm{J})$ cotyledon leaf, (M) leaf via application of new method were all inoculated onto elongation medium involved 0.4 $\mathrm{mg} / \mathrm{L} \mathrm{GA} 3$ for 15 days $(\mathrm{bar}=1 \mathrm{~cm})$. 
Table 1. Regeneration efficiency of various TDZ concentrations on inducing adventitious bud from different explants of J. curcas by conventional approach.

\begin{tabular}{ccccccc}
\hline Concentrations of & \multicolumn{3}{c}{ Regeneration rate $(\%)$} & \multicolumn{3}{c}{ Average number of buds per explant } \\
\cline { 2 - 7 } TDZ $(\mathrm{mg} / \mathrm{L})$ & Hypocotyl & Cotyledon leaf & Leaf & Hypocotyl & Cotyledon leaf & Leaf \\
\hline 0 & $0 \mathrm{~d}$ & $0 \mathrm{~d}$ & $0 \mathrm{~d}$ & $0 \mathrm{~d}$ & $0 \mathrm{~d}$ & $0 \mathrm{e}$ \\
0.1 & $9.91 \pm 1.81 \mathrm{c}$ & $20.53 \pm 3.21 \mathrm{c}$ & $18.54 \pm 2.36 \mathrm{c}$ & $1.29 \pm 0.13 \mathrm{c}$ & $3.51 \pm 0.72 \mathrm{c}$ & $1.94 \pm 0.32 \mathrm{~d}$ \\
0.25 & $18.83 \pm 1.93 \mathrm{~b}$ & $26.87 \pm 1.31 \mathrm{bc}$ & $33.39 \pm 3.55 \mathrm{~b}$ & $1.82 \pm 0.35 \mathrm{~b}$ & $4.65 \pm 0.53 \mathrm{~b}$ & $3.34 \pm 0.26 \mathrm{~b}$ \\
0.5 & $31.97 \pm 2.38 \mathrm{a}$ & $42.39 \pm 5.14 \mathrm{a}$ & $41.74 \pm 2.18 \mathrm{a}$ & $3.05 \pm 0.32 \mathrm{a}$ & $6.53 \pm 0.37 \mathrm{a}$ & $4.21 \pm 0.37 \mathrm{a}$ \\
1 & $22.75 \pm 4.06 \mathrm{~b}$ & $31.50 \pm 2.50 \mathrm{~b}$ & $27.26 \pm 3.42 \mathrm{~b}$ & $2.16 \pm 0.25 \mathrm{~b}$ & $5.79 \pm 0.68 \mathrm{a}$ & $2.58 \pm 0.12 \mathrm{c}$ \\
\hline
\end{tabular}

Values represent means \pm SD (standard deviation) of 35 explants per treatment in 3 independent experiments.

* Data in the same column followed by various letters are significant difference (Duncan's test at $\mathrm{p}$ $\leq 5 \%$ level).
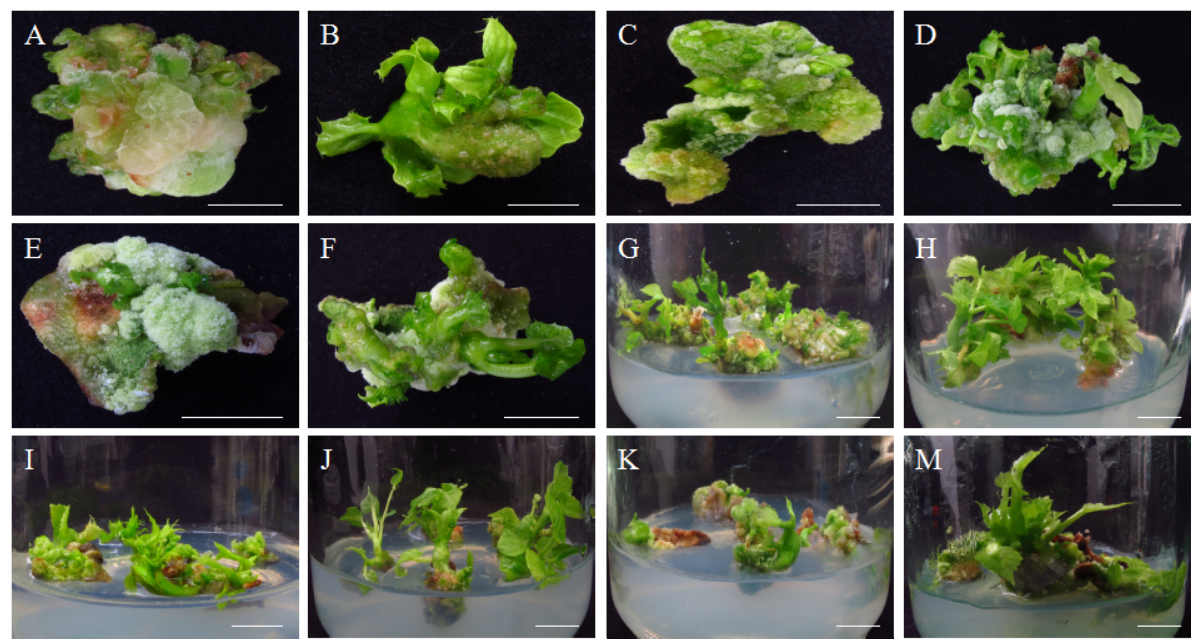

Fig. 1 Effect of adventitious buds regeneration and elongation from three kinds of explants in J. curcas.

\subsection{Regeneration of Shoot Buds from Explants Treated with TDZ Before Culture}

The effects of adventitious buds regeneration were influenced by the concentrations of TDZ solution visibly. Comparative analysis of the results shown in Table 2 and Figure 1(A-F), the best induction rate of adventitious buds regeneration $(74.39 \%-86.44 \%)$ and the maximum number of regenerated adventitious buds per explant (6.32-11.22) were obtained, when $20 \mathrm{mg} / \mathrm{L}$ of TDZ solution was applied; what's more, the regenerated buds were more healthy and stronger than those buds induction by the conventional approach (Figure 1(A-F)).

Table 2. Result of various TDZ concentrations on adventitious buds regeneration from three types of explants of J. curcas.

\begin{tabular}{ccccccc}
\hline $\begin{array}{c}\text { Concentrations of } \\
\text { TDZ }(\mathrm{mg} / \mathrm{L})\end{array}$ & \multicolumn{3}{c}{ Regeneration rate(\%) } & \multicolumn{3}{c}{ Average number of buds per explant } \\
\cline { 2 - 7 } & Hypocotyl & Cotyledon leaf & Leaf & Hypocotyl & Cotyledon leaf & Leaf \\
\hline 0 & $0 \mathrm{f}$ & 0f & 0f & $0 \mathrm{e}$ & $0 \mathrm{~g}$ & $0 \mathrm{e}$ \\
5 & $40.56 \pm 3.57 \mathrm{~d}$ & $41.38 \pm 3.12 \mathrm{~d}$ & $36.23 \pm 3.25 \mathrm{~d}$ & $4.19 \pm 0.62 \mathrm{~d}$ & $4.56 \pm 0.38 \mathrm{e}$ & $3.48 \pm 0.27 \mathrm{c}$ \\
10 & $52.45 \pm 4.24 \mathrm{c}$ & $57.23 \pm 2.99 \mathrm{c}$ & $49.28 \pm 3.46 \mathrm{c}$ & $6.78 \pm 0.54 \mathrm{~b}$ & $6.52 \pm 0.29 \mathrm{~d}$ & $4.56 \pm 0.34 \mathrm{~b}$ \\
20 & $82.05 \pm 2.38 \mathrm{a}$ & $86.44 \pm 4.82 \mathrm{a}$ & $74.39 \pm 2.89 \mathrm{a}$ & $10.03 \pm 0.67 \mathrm{a}$ & $11.22 \pm 0.51 \mathrm{a}$ & $6.32 \pm 0.48 \mathrm{a}$ \\
30 & $64.44 \pm 3.85 \mathrm{~b}$ & $68.37 \pm 3.47 \mathrm{~b}$ & $61.42 \pm 3.75 \mathrm{~b}$ & $7.48 \pm 0.34 \mathrm{~b}$ & $9.49 \pm 0.16 \mathrm{~b}$ & $4.41 \pm 0.22 \mathrm{~b}$ \\
60 & $52.96 \pm 3.14 \mathrm{c}$ & $52.14 \pm 2.58 \mathrm{c}$ & $46.24 \pm 4.34 \mathrm{c}$ & $5.33 \pm 0.30 \mathrm{c}$ & $7.69 \pm 0.27 \mathrm{c}$ & $3.57 \pm 0.36 \mathrm{c}$ \\
120 & $23.61 \pm 2.78 \mathrm{e}$ & $25.64 \pm 2.78 \mathrm{e}$ & $22.46 \pm 4.21 \mathrm{e}$ & $3.75 \pm 0.43 \mathrm{~d}$ & $3.77 \pm 0.32 \mathrm{f}$ & $2.85 \pm 0.25 \mathrm{~d}$ \\
\hline
\end{tabular}

Values represent means \pm SD (standard deviation) of 35 explants per treatment in 3 independent experiments.

* Data in the same column followed by various letters are significant difference (Duncan's test at $p$ $\leq 5 \%$ level). 
For the purpose of studying the effect of TDZ process-time on the induction of adventitious buds regeneration, explants were soaked in $20 \mathrm{mg} / \mathrm{L}$ of TDZ solution for different time before inoculation on MS medium without any hormones. The experimental results showed that the effect of adventitious buds regeneration and the response of different explants were both affected by process-time observably (Table 3). After incubation of the explants in $20 \mathrm{mg} / \mathrm{L} \mathrm{TDZ}$ solution for 20 min, the best regeneration rate $(74.39 \%-86.44 \%)$ and the highest quantity of regenerated buds per explant (6.32-11.22) were obtained (Table 3 and Figure 2 (B, D and F)). Comparing to the conventional culture method in our research, these regeneration rate and average number of buds per explant were improved severally by $32.65 \%-49.94 \%$ and $4.21-7.11$, and these regenerated buds were healthier (Table 1, Table 3 and Figure $1 \mathrm{~A}-\mathrm{F}$ ).

Table 3. Results of different processing time on adventitious buds regeneration from three types of explants of J. curcas.

\begin{tabular}{cccccccc}
\hline $\begin{array}{c}\text { Treatment duration } \\
(\mathrm{min})\end{array}$ & \multicolumn{3}{c}{ Regeneration rate(\%) } & \multicolumn{3}{c}{ Average number of buds per explant } \\
\cline { 2 - 7 } & Hypocotyl & Cotyledon leaf & Leaf & Hypocotyl & Cotyledon leaf & Leaf \\
\hline 0 & $0 \mathrm{e}$ & $0 \mathrm{e}$ & $0 \mathrm{e}$ & $0 \mathrm{e}$ & $0 \mathrm{e}$ & $0 \mathrm{e}$ \\
5 & $55.61 \pm 3.37 \mathrm{~cd}$ & $35.11 \pm 1.54 \mathrm{~d}$ & $32.21 \pm 2.36 \mathrm{~d}$ & $5.46 \pm 0.52 \mathrm{~d}$ & $5.25 \pm 0.60 \mathrm{~d}$ & $2.18 \pm 0.29 \mathrm{~d}$ \\
10 & $70.56 \pm 3.27 \mathrm{~b}$ & $49.64 \pm 3.43 \mathrm{c}$ & $43.97 \pm 4.21 \mathrm{c}$ & $8.48 \pm 0.75 \mathrm{~b}$ & $6.38 \pm 0.57 \mathrm{bc}$ & $3.54 \pm 0.45 \mathrm{bc}$ \\
20 & $82.05 \pm 2.38 \mathrm{a}$ & $86.44 \pm 5.82 \mathrm{a}$ & $74.61 \pm 3.32 \mathrm{a}$ & $10.03 \pm 0.67 \mathrm{a}$ & $11.22 \pm 0.51 \mathrm{a}$ & $6.28 \pm 0.43 \mathrm{a}$ \\
40 & $61.51 \pm 4.81 \mathrm{c}$ & $57.87 \pm 2.26 \mathrm{~b}$ & $56.36 \pm 1.69 \mathrm{~b}$ & $6.99 \pm 0.32 \mathrm{c}$ & $7.00 \pm 0.13 \mathrm{~b}$ & $4.27 \pm 0.51 \mathrm{~b}$ \\
80 & $45.62 \pm 3.56 \mathrm{~d}$ & $45.22 \pm 3.35 \mathrm{c}$ & $37.68 \pm 2.67 \mathrm{~d}$ & $5.02 \pm 0.48 \mathrm{~d}$ & $6.19 \pm 0.39 \mathrm{c}$ & $3.36 \pm 0.32 \mathrm{c}$ \\
\hline
\end{tabular}

Values represent means \pm SD (standard deviation) of 35 explants per treatment in 3 independent experiments.

* Data in the same column followed by various letters are significant difference (Duncan's test at $\mathrm{p}$ $\leq 5 \%$ level).

\subsection{Results of Elongation of the Regenerated Shoot-Buds}

From the results summed up in table 4, the concentration of GA3 affected the elongation of the shoot-buds obviously. The best results of shoot-buds elongation from conventional approach $(1.08-1.12 \mathrm{~cm})$ and treatment of TDZ solution $(1.75-1.78 \mathrm{~cm})$ were gained respectively (Table 4), when $0.4 \mathrm{mg} / \mathrm{L} \mathrm{GA}_{3}$ was applied. What's more, the elongated effects of shoot-buds from TDZ treatment approach were better than the results of regenerated buds from conventional protocol (Table 4 and Figure 1 G-M).

Table 4. Results of various GA3 concentrations on shoot buds elongation.

\begin{tabular}{ccccccc}
\hline $\begin{array}{c}\text { Concentration } \\
\text { of } \mathrm{GA}_{3}(\mathrm{mg} / \mathrm{L})\end{array}$ & \multicolumn{3}{c}{ Buds from the traditional method } & \multicolumn{3}{c}{ Buds from TDZ treatment } \\
\cline { 2 - 7 } & Hypocotyl & Cotyledon leaf & Leaf & Hypocotyl & Cotyledon leaf & Leaf \\
\hline 0 & $0.56 \pm 0.08 \mathrm{c}$ & $0.55 \pm 0.12 \mathrm{c}$ & $0.53 \pm 0.09 \mathrm{c}$ & $0.96 \pm 0.10 \mathrm{~d}$ & $0.87 \pm 0.08 \mathrm{c}$ & $0.85 \pm 0.09 \mathrm{~d}$ \\
0.1 & $0.73 \pm 0.11 \mathrm{~b}$ & $0.81 \pm 0.09 \mathrm{~b}$ & $0.78 \pm 0.12 \mathrm{~b}$ & $1.26 \pm 0.11 \mathrm{c}$ & $1.18 \pm 0.15 \mathrm{~b}$ & $1.22 \pm 0.11 \mathrm{c}$ \\
0.2 & $0.88 \pm 0.09 \mathrm{~b}$ & $0.89 \pm 0.08 \mathrm{~b}$ & $0.84 \pm 0.10 \mathrm{~b}$ & $1.33 \pm 0.12 \mathrm{bc}$ & $1.29 \pm 0.21 \mathrm{~b}$ & $1.38 \pm 0.08 \mathrm{bc}$ \\
0.4 & $1.12 \pm 0.12 \mathrm{a}$ & $1.10 \pm 0.11 \mathrm{a}$ & $1.08 \pm 0.09 \mathrm{a}$ & $1.78 \pm 0.09 \mathrm{a}$ & $1.75 \pm 0.13 \mathrm{a}$ & $1.76 \pm 0.12 \mathrm{a}$ \\
0.6 & $0.89 \pm 0.08 \mathrm{~b}$ & $0.93 \pm 0.09 \mathrm{ab}$ & $0.91 \pm 0.08 \mathrm{ab}$ & $1.62 \pm 0.07 \mathrm{ab}$ & $1.59 \pm 0.10 \mathrm{ab}$ & $1.64 \pm 0.07 \mathrm{ab}$ \\
0.8 & $0.79 \pm 0.10 \mathrm{~b}$ & $0.84 \pm 0.12 \mathrm{~b}$ & $0.82 \pm 0.07 \mathrm{~b}$ & $1.51 \pm 0.06 \mathrm{~b}$ & $1.48 \pm 0.18 \mathrm{ab}$ & $1.52 \pm 0.08 \mathrm{~b}$ \\
\hline
\end{tabular}

Values represent means \pm SD (standard deviation) of 35 explants per treatment in 3 independent experiments.

* Data in the same column followed by various letters are significant difference (Duncan's test at $\mathrm{p}$ $\leq 5 \%$ level).

In the end, the elongated shoots were placed into rooting medium for 20 days, and the whole plant were obtained successfully (Figure. 2A) and then transplanted in small-pots for further acclimation subsequently (Figure. 1B and C). 

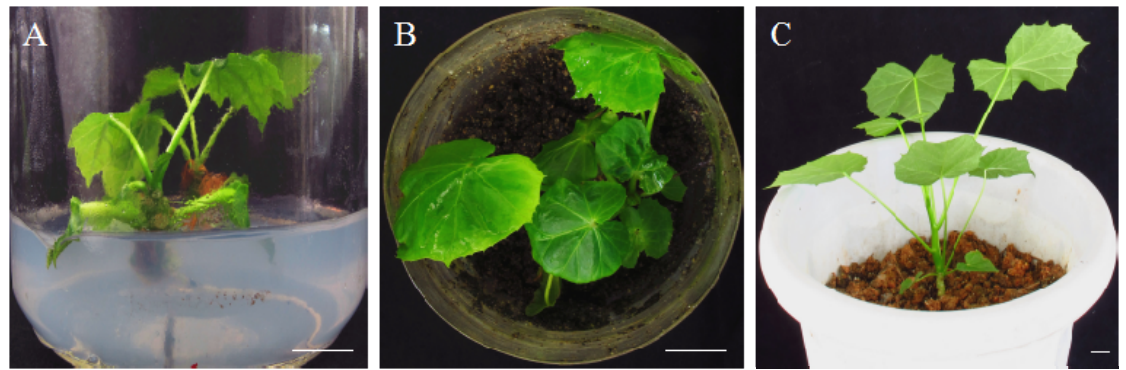

Fig. 2 Rooting, acclimation and transplantation of the regenerated plants.

(A) Rooting of elongated shoot buds on half-strength MS medium supplemented $0.1 \mathrm{mg} / \mathrm{L}$ IBA for 20 days; (B) 20-day-old acclimatized plant; (C) transplantation of complete plant in flowerpot for further acclimatization. (bars $=1 \mathrm{~cm}$ )

\section{Discussions}

TDZ is one of powerful cytokinins in woody plant tissue culture [12,13]. In the present study, explants might be just required a short period of hormonally triggered for induction of adventitious buds regeneration. Meanwhile, more efficient and better quality of regenerated adventitious buds were yielded by our new culture protocol, similar results were identified with the findings of our earlier research in soybean and $J$. curcas $[7,14]$. Furthermore, our results demonstrated that the achieved adventitious buds via our new menthod were able to gain to be elongated preferably and easily, while low regeneration rate and poor elongation of the adventitious buds were gained by utilizing the conventional approaches.

Previous studies had shown that the effect of adventitious buds regeneration could be enhanced significantly, as the explants were dealt with high concentrations of cytokinin solution [7,14]. All of our results implied that cytokinin might not be always indispensable to induce adventitious buds regeneration during the whole culture period. When the switch of cell division for redifferentiation was triggered, the superfluous cytokinin might be needless in the mediums and have some undesirable effects on the formation and development of adventitious buds.

\section{Conclusion}

An efficiency in vitro culture protocol for gaining regenerated intact plantlets from explants of $J$. curcas was shown in this paper. With the help of improved adventitious buds regeneration, an integrity plant could be obtained in about 65 days by applying the new culture method, but not at 90-140 days via conventional protocol. This efficiency and repeatable method might be used for the generation of transgenic plants through Agrobacterium-mediated transformation.

\section{Acknowledgements}

Corresponding author: YING LIU, Faculty of Agricultural Science, Guang Dong Ocean University, Haida Road \#1, Mazhang District, 524088, Zhanjiang, Guangdong, P. R. China, Email: liuying85168@126.com.

This work were supported by the Program for Scientific Research Start-up Funds of Guangdong Ocean University (R17023), the Project of Science and Technology of Zhanjiang City (2016B01004), the Project for Innovation and Strong School of Department of Education of Guangdong Province (2016KQNCX067), and the National and Provincial College Students Innovation and Entrepreneurship Training Program (CXXL2016015 and CXXL2017045).

\section{References}

[1]. Adebowale K.O., Adedire C.O. 2006. "Chemical composition and insecticidal properties of the underutilized Jatropha curcas seed oil,” African J. Biotechnol., 10: 901-906. 
[2]. Ghosh A., Chaudhary D.R., Reddy M.P., Rao S.N., Chikara J., Pandya J.B., Patolia J.S., Gandhi M.R., Adimurthy S., Vaghela N., Mishra S., Rathod M.R., Prakash A.R., Shethia B.D., Upadhyay S.C., Balakrishna V., Prakash C.R., Ghosh P.K.. 2007. "Prospects for Jatropha methyl ester (biodiesel) in India," Int. J. Environ. Stud., 64: 659-674.

[3]. Qu J., Mao H.Z., Chen W., Gao S.Q., Bai Y.N., Sun Y.W., Geng Y.F., Ye J. 2012. “Development of marker-free transgenic Jatropha plants with increased levels of seed oleic acid," Biotechnol. Biofuels., 5: 1-11.

[4]. Kajikawa M., Morikawa K., Inoue M., Widyastuti U., Suharsono S., Yokota A., Akashi K. 2012. "Establishment of bispyribac selection protocols for Agrobacterium tumefaciens- and Agrobacterium rhizogenes-mediated transformation of the oil seed plant Jatropha curcas L.," Plant Biotechnol., 29: 145-153.

[5]. Kumar N., Reddy M.P. 2012. "Thidiazuron (TDZ) induced plant regeneration from cotyledonary petiole explants of elite genotypes of Jatropha curcas: A candidate biodiesel plant," Ind. Crops Prod., 39: 62-68.

[6]. Zhang C., Fu S.P., Tang G.J., Hu X.W., Guo J.C.. 2013. "Factors influencing direct shoot regeneration from mature leaves of Jatropha curcas, an important biofuel plant," In Vitro Cell Dev. Biol.-Plant., 49: 529-540.

[7]. Liu Y., Tong X., Hui W.K., Liu T., Chen X.Y., Li J., Zhuang C.X., Yang Y.S., Liu Z.L. 2015. "Efficient culture protocol for plant regeneration from petiole explants of physiologically mature trees of Jatropha curcas L.," Biotechnol. Biotec. Eq., 29: 479-488.

[8]. Murashige T., Skoog F. 1962. "A revised medium for rapid growth and bioassays with tobacco tissue cultures," Physiol. Plant., 15: 473-479.

[9]. Deore A.C., Johnson T.S. 2008. "High-frequency plant regeneration from leaf-disc cultures of Jatropha curcas L. an important biodiesel plant," Plant Biotech. Rep., 2: 10-15.

[10]. Kumar N., Reddy M.P. 2012. "Thidiazuron (TDZ) induced plant regeneration from cotyledonary petiole explants of elite genotypes of Jatropha curcas: A candidate biodiesel plant," Ind. Crops Prod., 39: 62-68.

[11]. Liu Y., Liu G.X., Yang Y.L., Niu S.F., Yang F.G., Yang S.X., Tang J.N., Chen J.P. 2017. "Establishment of an efficient plant regeneration culture protocol and achievement of successful genetic transformation in Jatropha curcas L.," Acta Biol. Hung., 68: 428-442.

[12]. Kumar N., Reddy M.P. 2012. "Thidiazuron (TDZ) induced plant regeneration from cotyledonary petiole explants of elite genotypes of Jatropha curcas: A candidate biodiesel plant," Ind. Crops Prod., 39: 62-68.

[13]. Huetteman C.A., Preece J.E. 1993. "Thidiazuron: a potent cytokinin for woody plant tissue culture," Plant Cell Tiss. Organ., 33: 105-119.

[14]. Liu Y., Yu L., Zhang Q., Nian H., Guo Z.F., Yang Y.S. 2013. "High concentration short duration treatment of benzyladenine stimulates adventitious bud regeneration from hypocotyl explants in soybean," Adv. Mater. Res., 647: 331-335. 